\title{
An evaluation of the barotropic and internal tides in a high-resolution global ocean circulation model
}

\author{
J. F. Shriver, ${ }^{1}$ B. K. Arbic, ${ }^{2}$ J. G. Richman, ${ }^{1}$ R. D. Ray, ${ }^{3}$ E. J. Metzger, ${ }^{1}$ A. J. Wallcraft, ${ }^{1}$ \\ and P. G. Timko ${ }^{2}$ \\ Received 30 April 2012; revised 14 September 2012; accepted 15 September 2012; published 27 October 2012.
}

[1] Global comparisons of barotropic and internal tides generated in an eddy-resolving ocean circulation model are made with tidal estimates obtained from altimetric sea surface heights and an altimetry-constrained tide model. As far as we know, our Hybrid Coordinate Ocean Model (HYCOM) simulations shown here and in an earlier paper are the only published high-resolution global simulations to contain barotropic tides, internal tides, the general circulation, and mesoscale eddies concurrently. Comparing the model barotropic tide with a global data-assimilative shallow water tide model shows that the global tidal elevation differences are approximately evenly split between discrepancies in tidal amplitude and phase. Both the model and observations show strong generation of internal tides at a limited number of "hot spot" regions with propagation of beams of energy for thousands of kilometers away from the sources. The model internal tidal amplitudes compare well with observations near these energetic tidal regions. Averaged over these regions, the model and observation internal tide amplitude estimates agree to approximately $15 \%$ for the four largest semidiurnal constituents and $23 \%$ for the four largest diurnal constituents. Away from the hot spots, the comparison between the model and altimetric amplitude is not as good due, in part, to two problems, errors in the model barotropic tides and overestimation of the altimetric tides in regions of strong mesoscale eddy activity. Examining the general energy distribution of the simulated internal tide is an important first step in the evaluation of internal tides in HYCOM.

Citation: Shriver, J. F., B. K. Arbic, J. G. Richman, R. D. Ray, E. J. Metzger, A. J. Wallcraft, and P. G. Timko (2012), An evaluation of the barotropic and internal tides in a high-resolution global ocean circulation model, J. Geophys. Res., 117, C10024, doi:10.1029/2012JC008170.

\section{Introduction}

[2] Oceanic internal tides are internal waves with tidal periodicity that are generated by the interaction of barotropic tidal currents with variable bottom topography. Freely propagating diurnal internal tides are theoretically constrained to the approximate latitude range $30^{\circ} \mathrm{S}-30^{\circ} \mathrm{N}$ [ Gill, 1982 , p. 258], with semidiurnal tides found in this range and higher latitudes. They play a key role in dissipating tidal energy and mixing in the deep ocean [e.g., Egbert and Ray, 2000; Jayne and St. Laurent, 2001; Simmons et al., 2004].

[3] A first attempt to resolve internal tides, along with barotropic tides and the eddying general circulation, in a

\footnotetext{
${ }^{1}$ Naval Research Laboratory, Stennis Space Center, Mississippi, USA.

${ }^{2}$ Department of Earth and Environmental Sciences, University of Michigan, Ann Arbor, Michigan, USA.

${ }^{3}$ NASA Goddard Space Flight Center, Greenbelt, Maryland, USA.

Corresponding author: J. F. Shriver, Naval Research Laboratory, Stennis Space Center, MS 39529, USA. (jay.shriver@nrlssc.navy.mil)

This paper is not subject to U.S. copyright.

Published in 2012 by the American Geophysical Union.
}

global ocean circulation model is described by Arbic et al. [2010]. The simulations in the work by Arbic et al. [2010] and in this study utilize the Hybrid Coordinate Ocean Model (HYCOM), which is being developed by the United States Navy as an ocean nowcast/forecast model. These simulations employ both tidal and atmospheric forcing, in contrast to earlier global baroclinic tide simulations that employed only tidal forcing [Arbic et al., 2004; Simmons et al., 2004]. Atmospheric forcing allows for a more realistic horizontally varying stratification in HYCOM, in contrast to the uniform stratification employed in the work by Arbic et al. [2004] and Simmons et al. [2004].

[4] The HYCOM tides simulations, which thus far have been run only in forward (nonassimilative) mode, are continually being updated, especially with regards to the parameterized topographic wave drag. As a result, the simulations utilized here are not identical to those by Arbic et al. [2010], though the accuracy of the barotropic tide is comparable. In the simulation analyzed here we capture $93.2 \%$ of the sea surface elevation variance of the eight largest tidal constituents in the standard set of 102 pelagic tide gauges [Shum et al., 1997]; in the work by Arbic et al. [2010] they captured $92.6 \%$.

[5] As far as we know, our HYCOM simulations are the only published global simulations to contain barotropic 


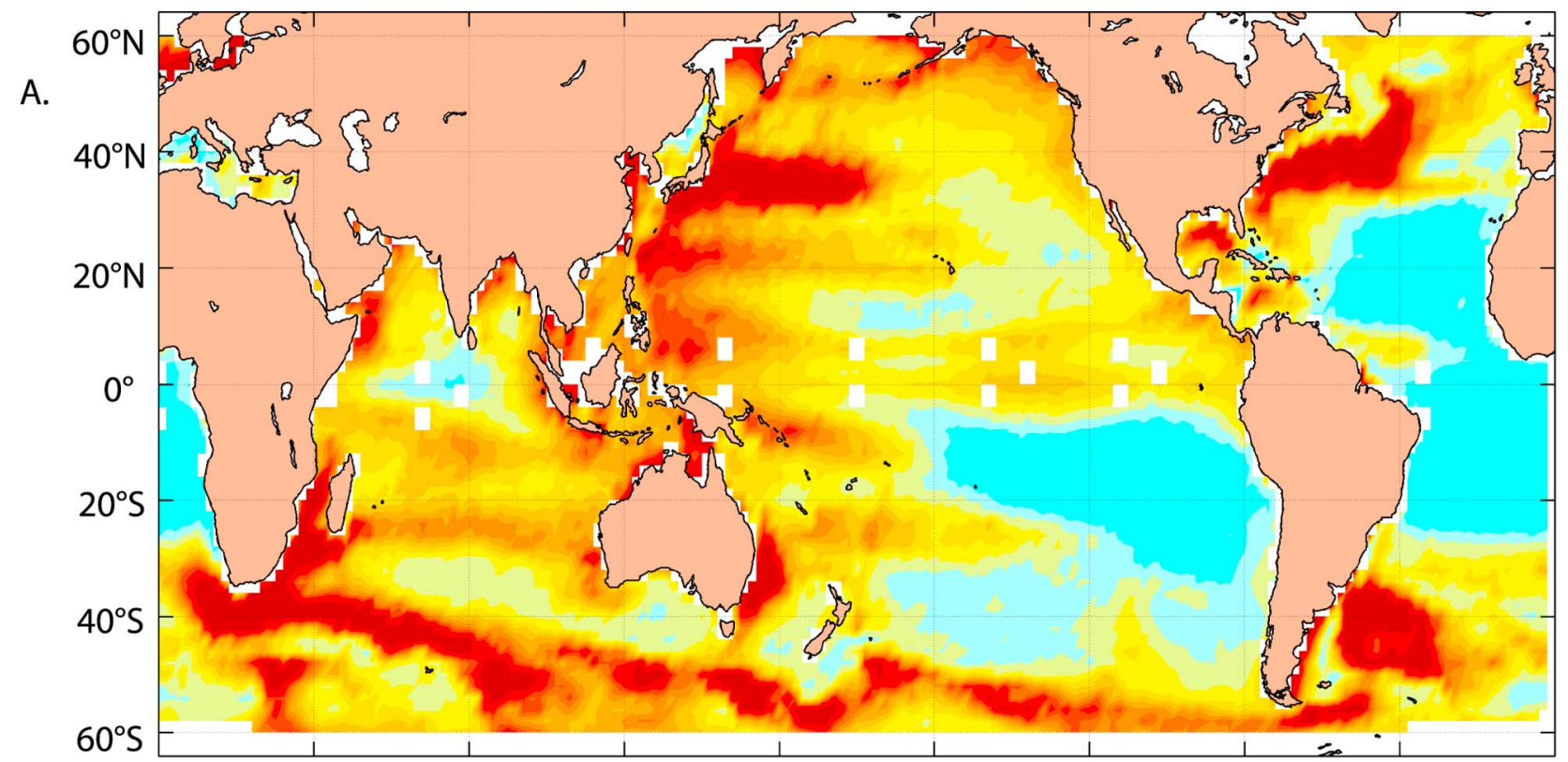

B.
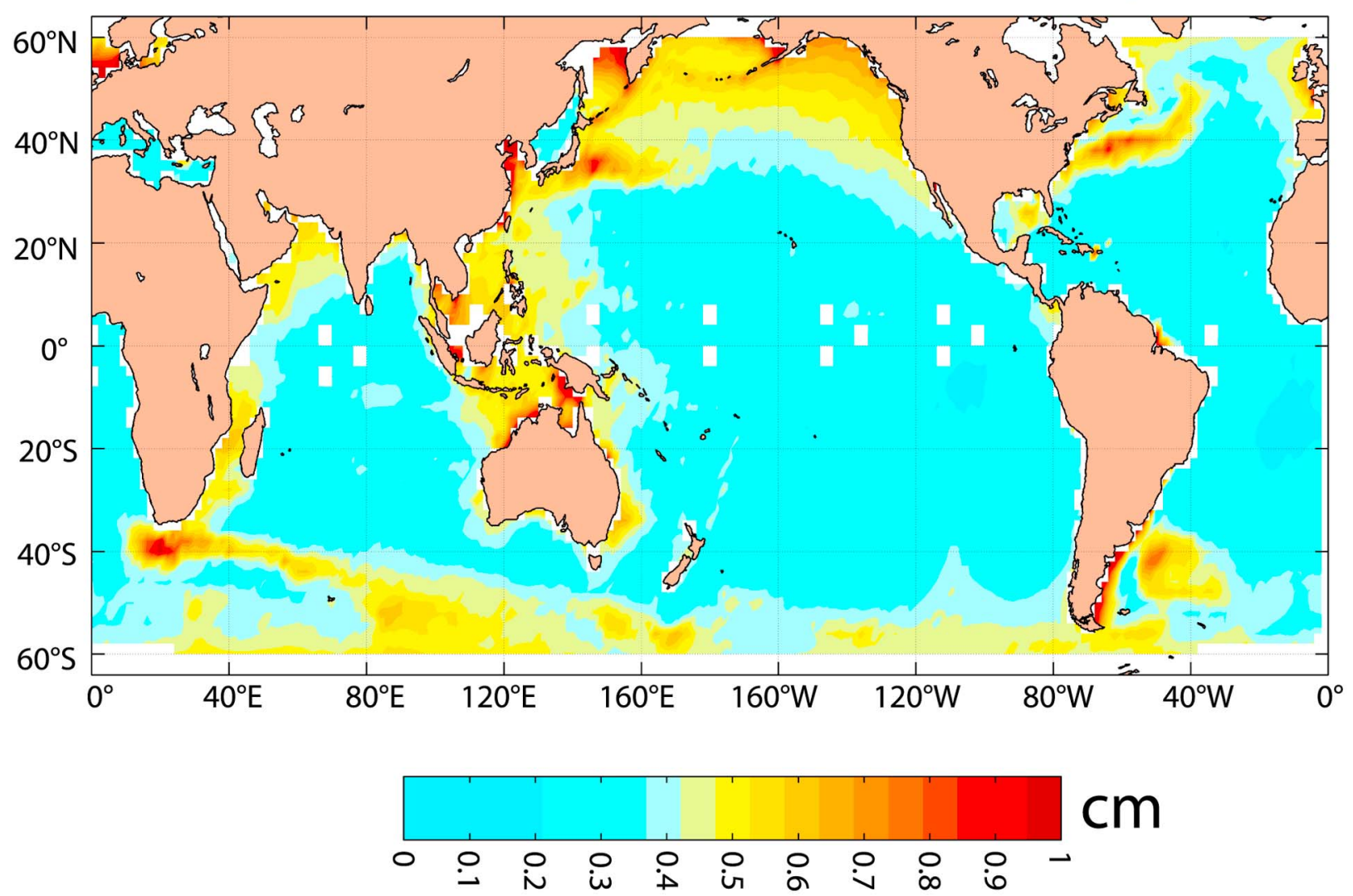

Figure 1. Standard errors $(\mathrm{cm})$ of altimeter-based along-track estimates of the $\mathrm{O}_{1}$ surface tidal elevation (a) without and (b) with prior correction of the altimetry for nontidal sea surface variability. The largest errors in Figure 1a reach $3 \mathrm{~cm}$. Results for $\mathrm{M}_{2}$ are very similar. Approximately 17 years of T/P and Jason altimetry are used in the tidal estimation. See also Carrère et al. [2004, Figure 5].

tides, internal tides, the general circulation, and mesoscale eddies concurrently and at high horizontal resolution. This paper examines how accurately HYCOM, forced only by atmospheric forcing and the astronomical tidal potential, can simulate the global barotropic tide fields in comparison to an altimetry-constrained barotropic tide model [Egbert et al., 1994] and the global internal tide fields in comparison to an observed data set. The only global observations of barotropic and internal tides are based on satellite altimetry. We compare the barotropic tides in HYCOM to output from an 


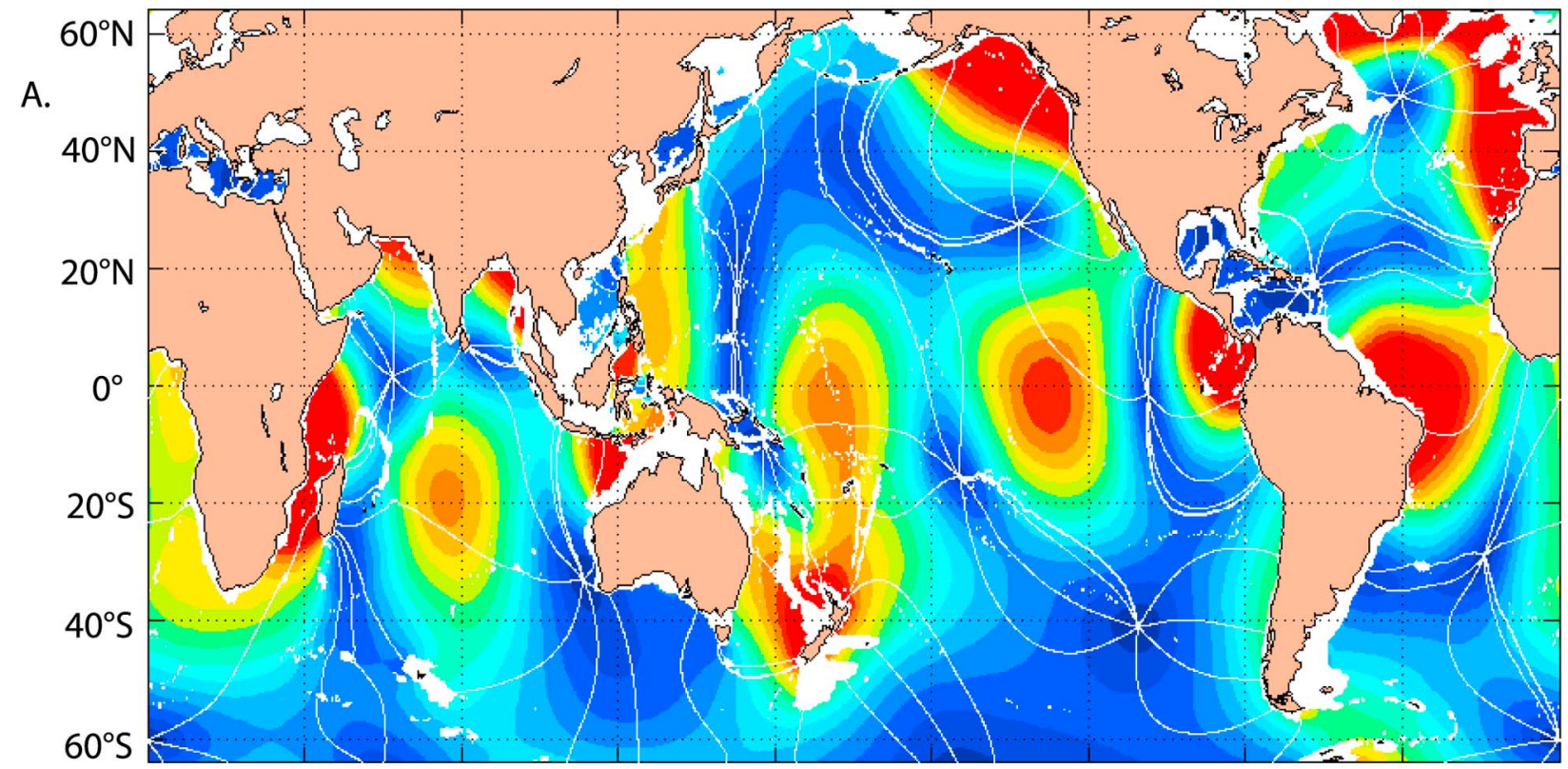

B.
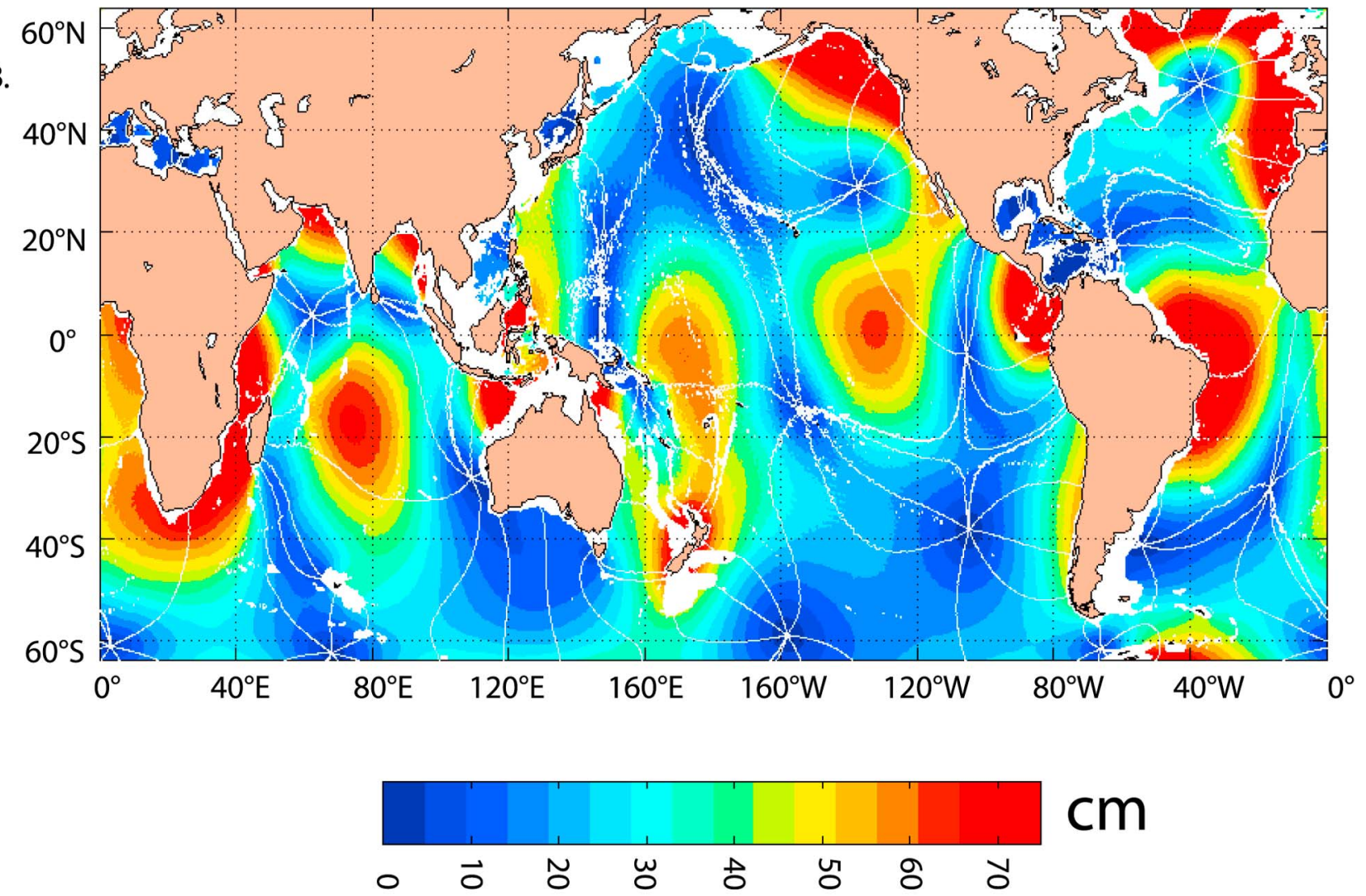

Figure 2. Amplitude (cm) of $\mathrm{M}_{2}$ surface tidal elevation in (a) TPXO7.2 (an update to that described by Egbert et al. [1994]), a barotropic tide model constrained by satellite altimetry, and (b) HYCOM simulations in which the tide is unconstrained by satellite altimetry. Lines of constant phase plotted every $45^{\circ}$ in Figures $2 \mathrm{a}$ and $2 \mathrm{~b}$ are overlaid in white.

altimetry-constrained barotropic tide model [Egbert et al., 1994] and the internal tides in HYCOM to results from an analysis of along-track satellite altimetry data [Ray and Mitchum, 1996]. Several previous comparisons of modeled and observed internal tides have utilized regional models of strong internal tide generation sites forced by specified barotropic tides at their horizontal boundaries [e.g., Cummins et al., 2001; Kang et al., 2000; Merrifield et al., 2001]. 

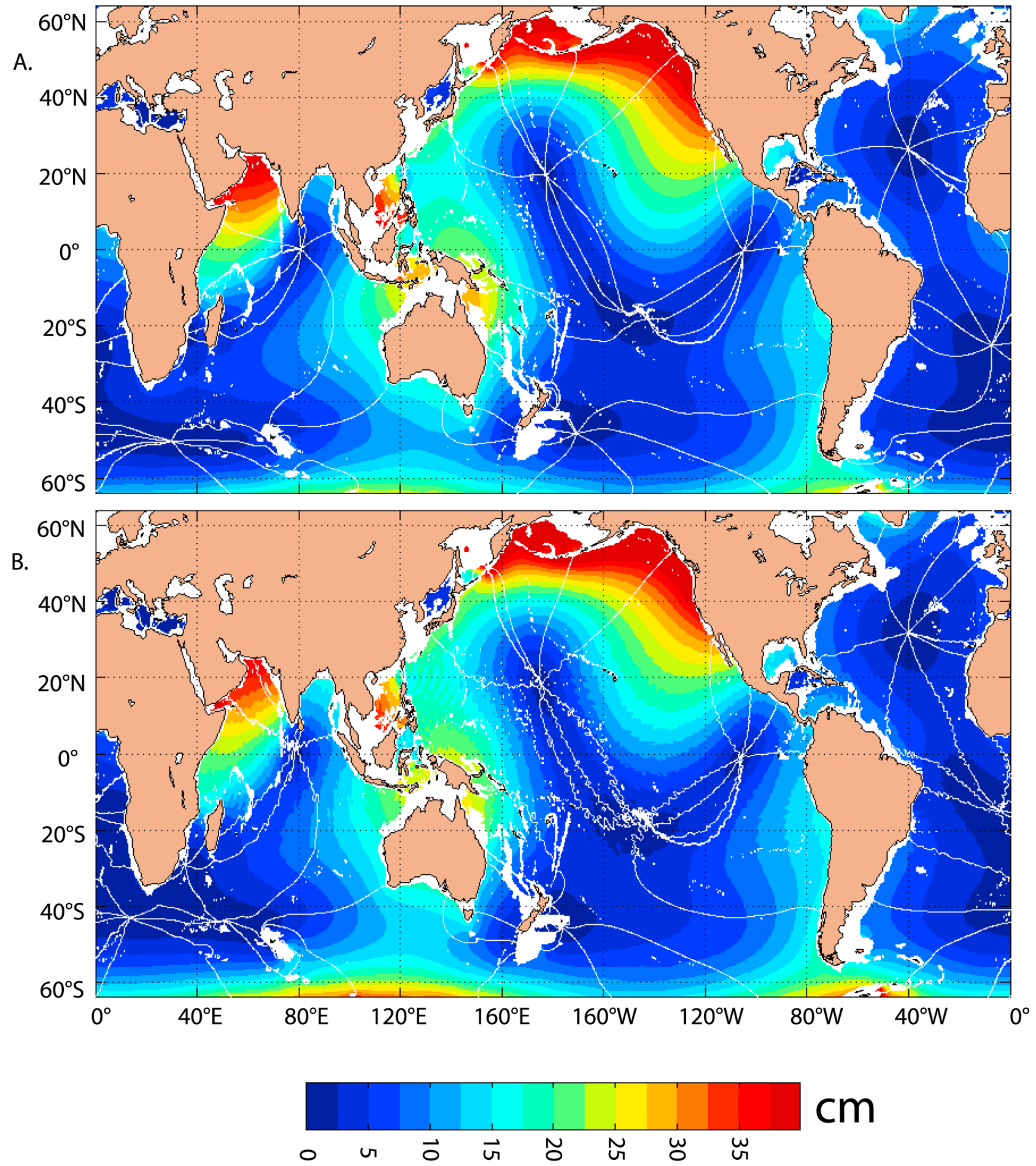

Figure 3. Same as Figure 2 but for the $\mathrm{K}_{1}$ tidal constituent.

Arbic et al. [2010] validated the HYCOM barotropic tides via comparison to a standard set of pelagic tide gauges [Shum et al., 1997], which obviously offer much less uniform coverage of the global ocean than satellite altimetry. The validation of internal tides by Arbic et al. [2010] was done for only one tidal constituent $\left(\mathrm{M}_{2}\right)$ and for a limited area around Hawaii. Our results represent the first global quantitative comparison of the simulated internal tide field to an observed data set.

\section{Model and Data}

[6] As in the work by Arbic et al. [2010], the HYCOM simulation examined in this study utilizes geopotential tidal 
Table 1. Global-Averaged Amplitude, Phase, and Total RMS Errors of HYCOM Surface Tidal Elevations Measured Against TPXO7.2, Following the Error Derivation in (3) ${ }^{\mathrm{a}}$

\begin{tabular}{lccc}
\hline & Amplitude Error & Phase Error & Total Error \\
\hline $\mathrm{M}_{2}$ & 5.560 & 4.999 & 7.477 \\
$\mathrm{~S}_{2}$ & 2.807 & 3.544 & 4.522 \\
$\mathrm{~N}_{2}$ & 0.810 & 0.794 & 1.134 \\
$\mathrm{~K}_{2}$ & 0.770 & 1.166 & 1.397 \\
$\mathrm{~K}_{1}$ & 1.555 & 1.627 & 2.251 \\
$\mathrm{O}_{1}$ & 1.714 & 1.467 & 2.257 \\
$\mathrm{P}_{1}$ & 0.498 & 0.543 & 0.737 \\
$\mathrm{Q}_{1}$ & 0.379 & 0.371 & 0.530 \\
\hline
\end{tabular}

${ }^{\mathrm{a} U n i t s}$ are in centimeters.

forcing for $\mathrm{M}_{2}, \mathrm{~S}_{2}, \mathrm{~N}_{2}$, and $\mathrm{K}_{2}$ (the four largest semidiurnal constituents), and $\mathrm{K}_{1}, \mathrm{O}_{1}, \mathrm{P}_{1}$, and $\mathrm{Q}_{1}$ (the four largest diurnal constituents), a scalar self-attraction and loading correction (SAL) [Ray, 1998], a parameterized topographic wave drag, 32 layers in the vertical direction and a nominal horizontal resolution of $1 / 12.5^{\circ}$ at the equator. For the tides, there are only two adjustable parameters, the scalar SAL and the topographic drag amplification factor. These two parameters are adjusted, using a one-layer barotropic $\mathrm{M}_{2}$ only version of the model, to minimize the differences between the model $\mathrm{M}_{2}$ tide and the 102 pelagic tide gauges. All other parameters are the same as the parameters in the nontidal global model at the same resolution. Therefore, no further tuning was done specifically for the internal tides in the model. Arbic et al. [2010] describe the necessity for a parameterized topographic wave drag in global baroclinic tide models. In the simulation by Arbic et al. [2010], the topographic wave drag from Arbic et al. [2004] is multiplied by a factor of 6 giving e-folding time scales from the drag of $1.5 \mathrm{~h}$ to 6 days with no topographic wave drag over $73 \%$ of the world ocean. To mitigate instability from the extremely short efolding time scales, the wave drag e-folding time in our simulation is clipped at $24 \mathrm{~h}$ and the scaling factor increased to 12 to keep the average wave drag the same as in the work by Arbic et al. [2010]. For additional details on global eddyresolving HYCOM the reader is referred to Metzger et al. [2010].

[7] The model was run interannually over the period 7/200312/2010 using 3-hourly Fleet Numerical Meteorology and Oceanography Center Navy Operational Global Atmospheric Prediction System (FNMOC NOGAPS) [Rosmond et al., 2002] atmospheric forcing with wind speeds scaled to be consistent with QuikSCAT observations. Total sea surface height (SSH) snapshots were saved once per hour for this period. Since the majority of low vertical mode internal tide energy in altimetry is thought to be stationary [Ray and Zaron, 2011], we used model results from calendar year 2006 for this study.

[8] The HYCOM tidal sea surface elevation amplitude and phases were calculated as a complex amplitude using standard harmonic analysis [Foreman, 1977] applied to the HYCOM total SSH. The HYCOM tidal sea surface elevations are dominated by the barotropic tides, and are compared to a hydrodynamic model of the barotropic tides constrained by satellite altimetry (TPXO7.2, an update to that described by Egbert et al. [1994]). In this comparison, referred to hereafter as the "barotropic" comparison, the HYCOM results are interpolated to the lower-resolution TPXO grid.
[9] The internal tides in HYCOM are compared to altimetric internal tidal estimates derived from approximately 17 years of along-track TOPEX/POSEIDON and Jason satellite altimetry. To facilitate the comparison of internal tides in HYCOM with those in along-track altimetry data (hereafter, the "internal tide" comparisons), the complex amplitudes from the HYCOM tidal analysis are first interpolated to the along-track altimeter data locations. The internal tide complex amplitudes are recovered from the HYCOM and along-track altimeter analyses via band-pass filtering to permit wavelengths in the $50-400 \mathrm{~km}$ range. This range spans the length scales of the low-mode internal waves that HYCOM is able to resolve. All filtering and interpolating is done in complex space, with amplitude discussed in section 3 representing the positive definite magnitude. All analyses discussed in this paper focus on locations where the seafloor depth exceeds $1500 \mathrm{~m}$.

[10] For the satellite data, a response analysis [Cartwright and Ray, 1990] is used for the diurnal and semidiurnal bands, supplemented with estimates of the annual cycle and a single quarter-diurnal constituent. Solid earth tides (including the component arising from crustal loading) are removed via models. Tides are independently estimated point-by-point along the satellite tracks [Ray and Mitchum, 1996].

[11] As is well known, the satellite repeat period (9.9156 days) aliases all diurnal and subdiurnal tides to long periods: roughly 60 days for the two largest semidiurnal tides and 173 days for $\mathrm{K}_{1}$. The alias periods for the tides are similar to the mesoscale eddy variability time scales, and the spatial scales for low vertical mode internal waves of tidal period are similar to the spatial scales of mesoscale eddies. Real ocean variability at these alias periods can directly corrupt tidal estimation ("mesoscale contamination") when attempted at single locations along track.

[12] In fact, extraction of internal tide signals from altimetry is especially problematic in regions of high mesoscale variability [Tierney et al., 1998; Carrère et al., 2004]. This difficulty is reflected in our estimation standard errors, shown in Figure 1a for the $\mathrm{O}_{1}$ constituent. It is clear that the largest errors are associated with strong boundary currents. Although the standard errors shown here formally pertain to all wave numbers, the spatial scales of boundary currents can drive these largest errors into the internal tide band. The magnitudes of the errors can greatly exceed expected internal tide amplitudes (see section 3.2), making signal extraction in these regions very difficult.

[13] The problem of mesoscale contamination can be reduced, but not eliminated, by removing from the altimetry a prior estimate of the nontidal sea surface heights [Ray and Byrne, 2010]. We have here used weekly gridded sea level anomalies derived from a multisatellite analysis [Pascual et al., 2006]. The resulting tidal standard errors, shown in Figure 1b, are much reduced with this technique. However, these reduced amplitudes can still reach $1 \mathrm{~cm}$ in highmesoscale regions, which can exceed internal tide amplitudes, as is evident below.

\section{Model-Data Comparisons}

\subsection{Barotropic Tide}

[14] Since the internal tides in HYCOM are generated by the interaction of the barotropic tide with the bottom 


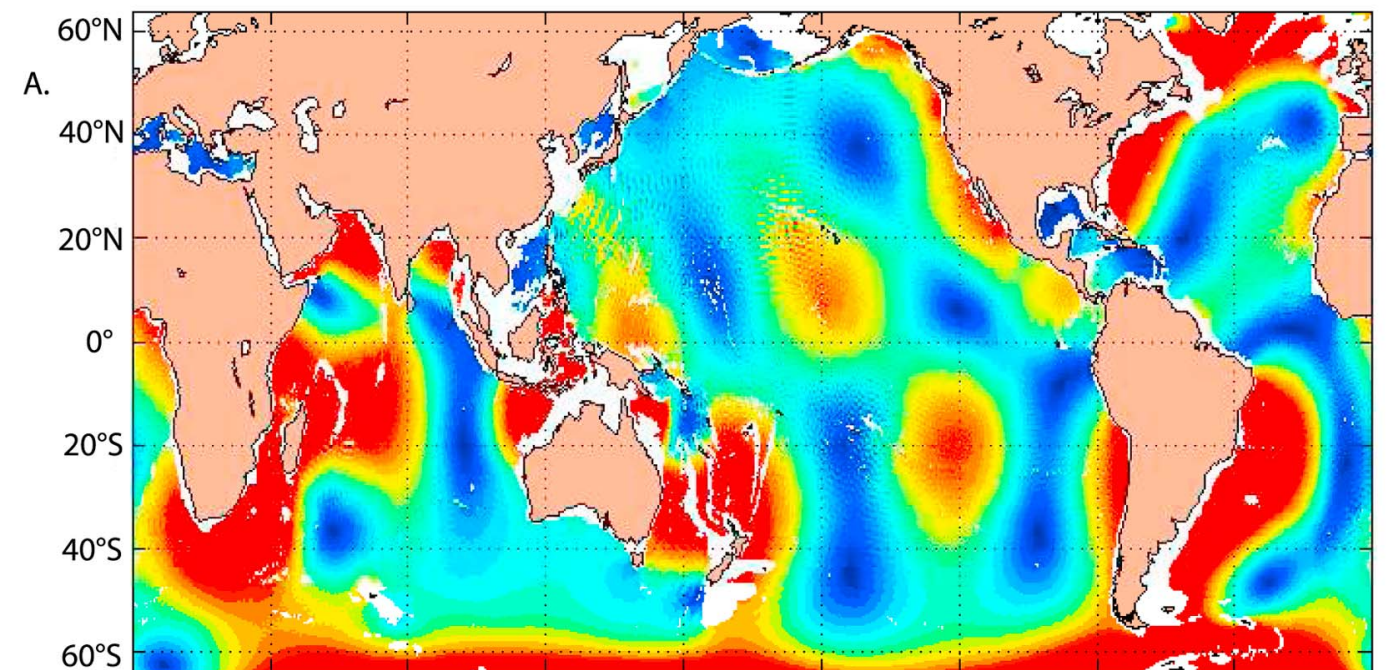

B.
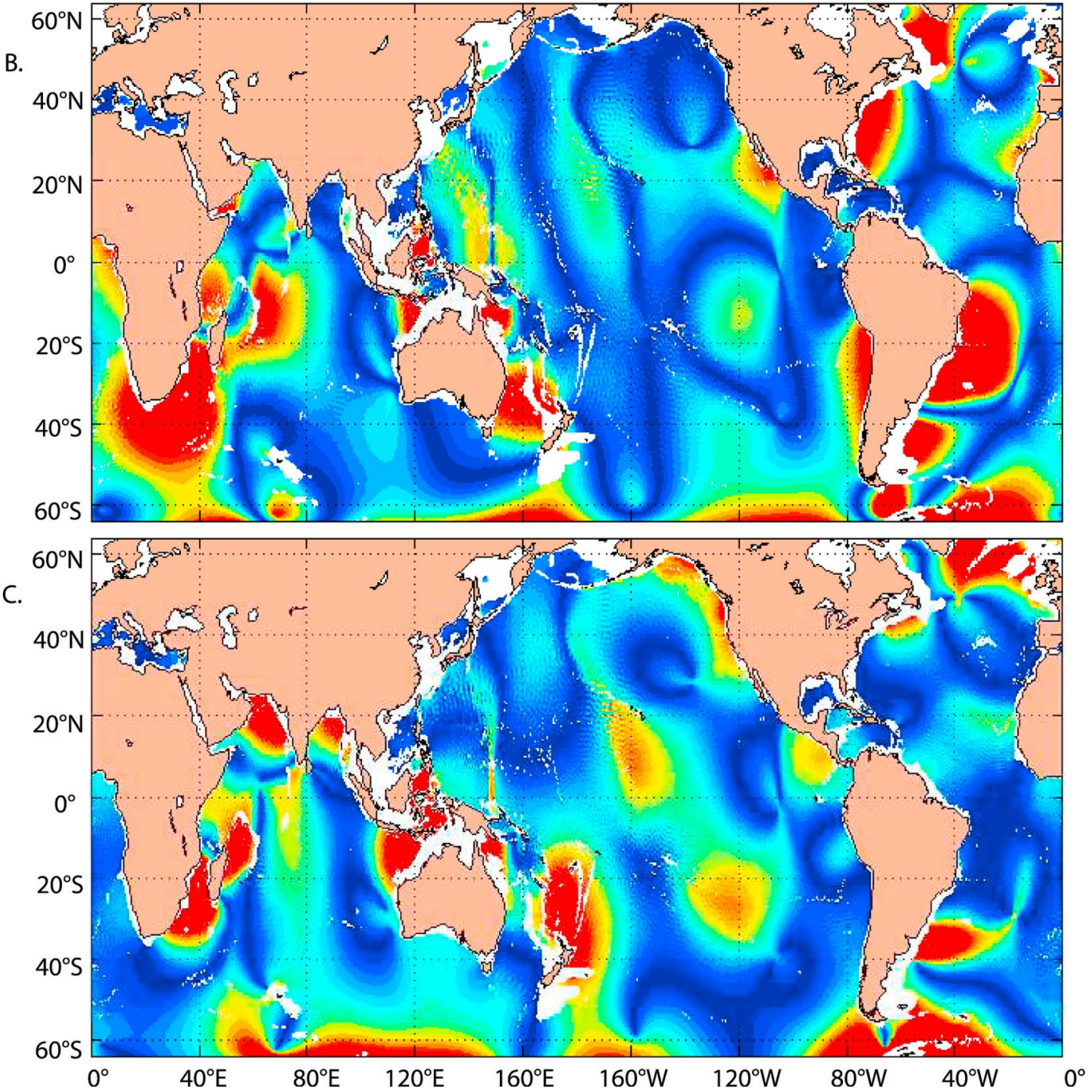

Figure 4. (a) $\mathrm{M}_{2}$ surface tidal elevation error for the HYCOM surface tidal elevation measured against TPXO. The contributions to the surface tidal elevation error resulting from errors in (b) tidal amplitude only and (c) amplitude-weighted phase following the derivation in (3). Units are in centimeters. 

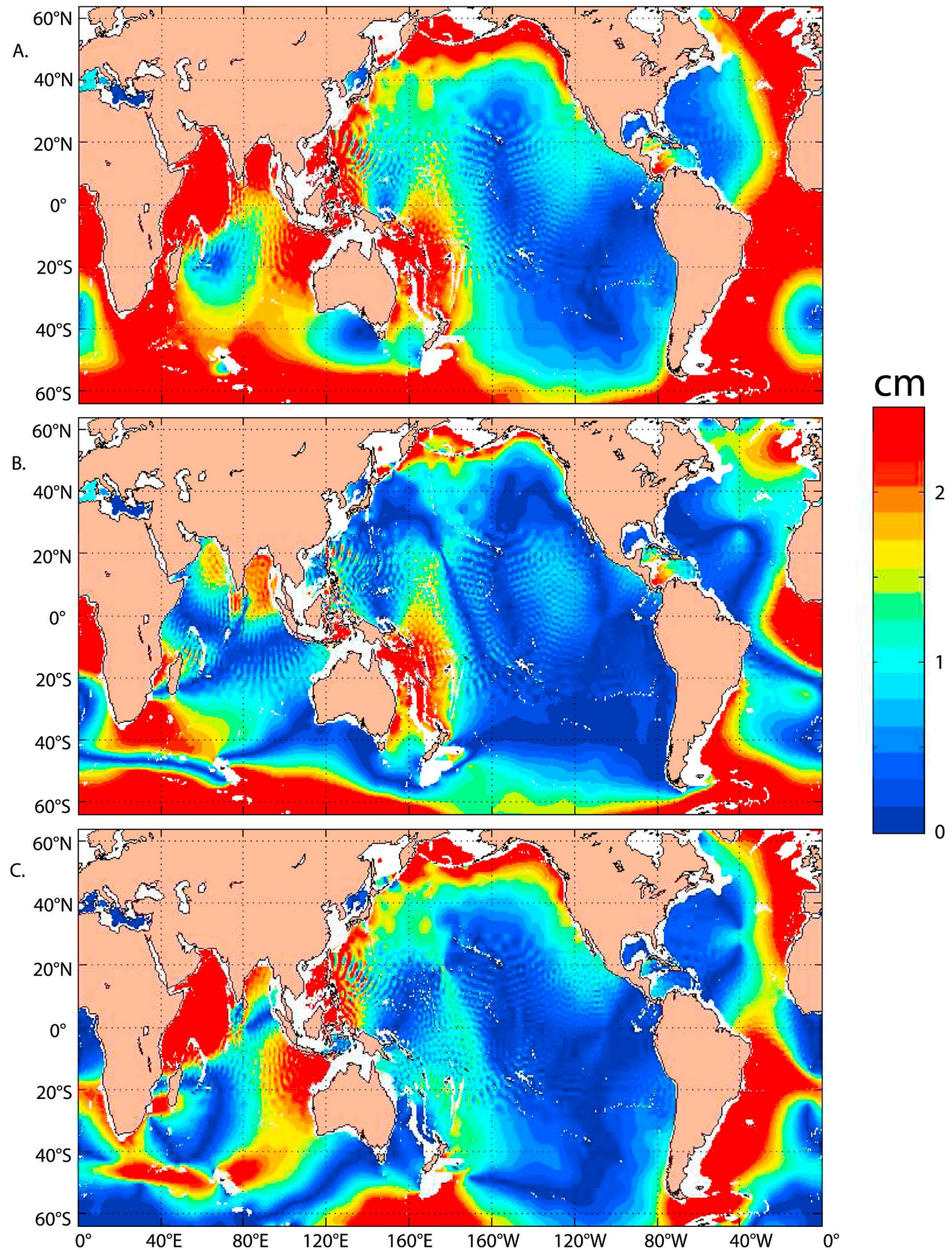

Figure 5. Same as Figure 4, but for the $\mathrm{K}_{1}$ tidal constituent. 


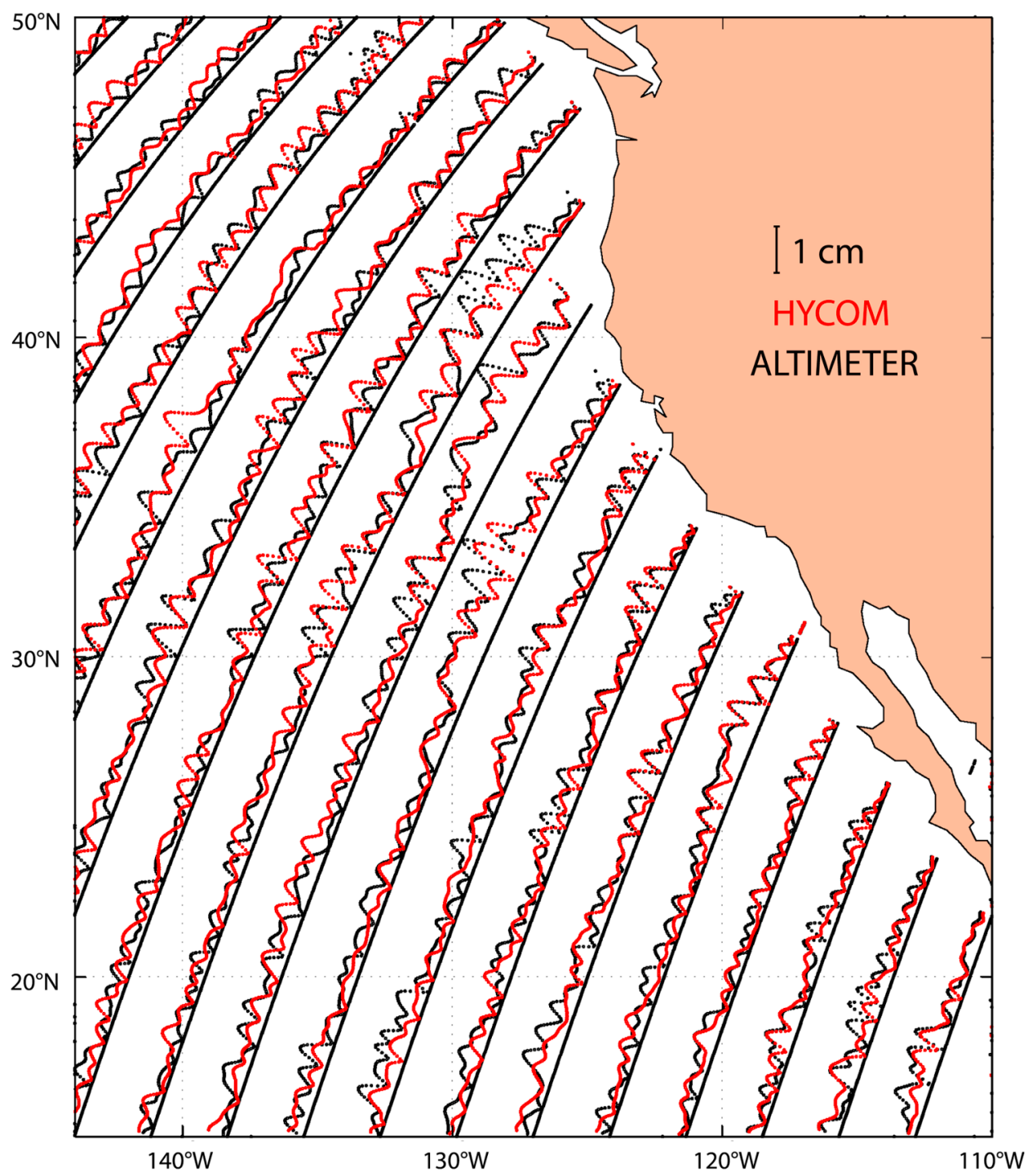

Figure 6. $\mathrm{M}_{2}$ internal tide amplitude along ascending tracks from the HYCOM (red) and altimeter-based analysis (black). For each track, the line showing the coordinates of the track represents a zero amplitude for the tides on that track. The short-scale smoothness is due in part to the application of the band-pass filter and is not due to the response method used in the altimetric-based analysis.

topography, an accurate barotropic tide is needed in order to produce an accurate internal tide. To assess the accuracy of the simulated barotropic tide in HYCOM, each of its eight tidal constituents (computed from total SSH, which is dominated by the barotropic tide) are compared to those from an altimetry constrained barotropic tide model (TPXO7.2; an update to that described by Egbert et al. [1994]). A recent assessment of altimeter-constrained models [Ray et al., 2011] suggests $\mathrm{M}_{2}$ RMS errors of about $1.5 \mathrm{~cm}$ or less in the deep ocean and anywhere from two to ten times larger errors in shallow water, depending on location. The TPXO7.2 model has comparable statistics, while nonassimilative global tide models have much larger RMS errors.

[15] Results from this comparison for $\mathrm{M}_{2}$ and $\mathrm{K}_{1}$ (the largest amplitude semidiurnal and diurnal constituents) are shown in Figures 2 and 3, respectively. Qualitatively the tidal amplitudes and phases in HYCOM are similar to the results from TPXO, but there are differences. One difference is that HYCOM includes internal waves, resulting in small amplitude, small horizontal scale perturbations to both the amplitudes and phases in Figures $2 b$ and $3 b$. Another difference is that our HYCOM tide simulation is a forward (nonassimilative) calculation and our barotropic tides therefore are not as accurate as those in barotropic data-assimilative global tidal models such as TPXO, or in regional models forced by data-assimilative barotropic models at their boundaries [e.g., Cummins et al., 2001; Merrifield et al., 2001].

[16] To quantify the differences between HYCOM and TPXO surface tidal elevations, we calculate the mean square error (MSE),

$$
M S E=\frac{1}{2}\left|A_{H Y C O M} e^{i \phi_{\text {HYCOM }}}-A_{\text {TPXO }} e^{i \phi_{\text {TPXO }}}\right|^{2}
$$




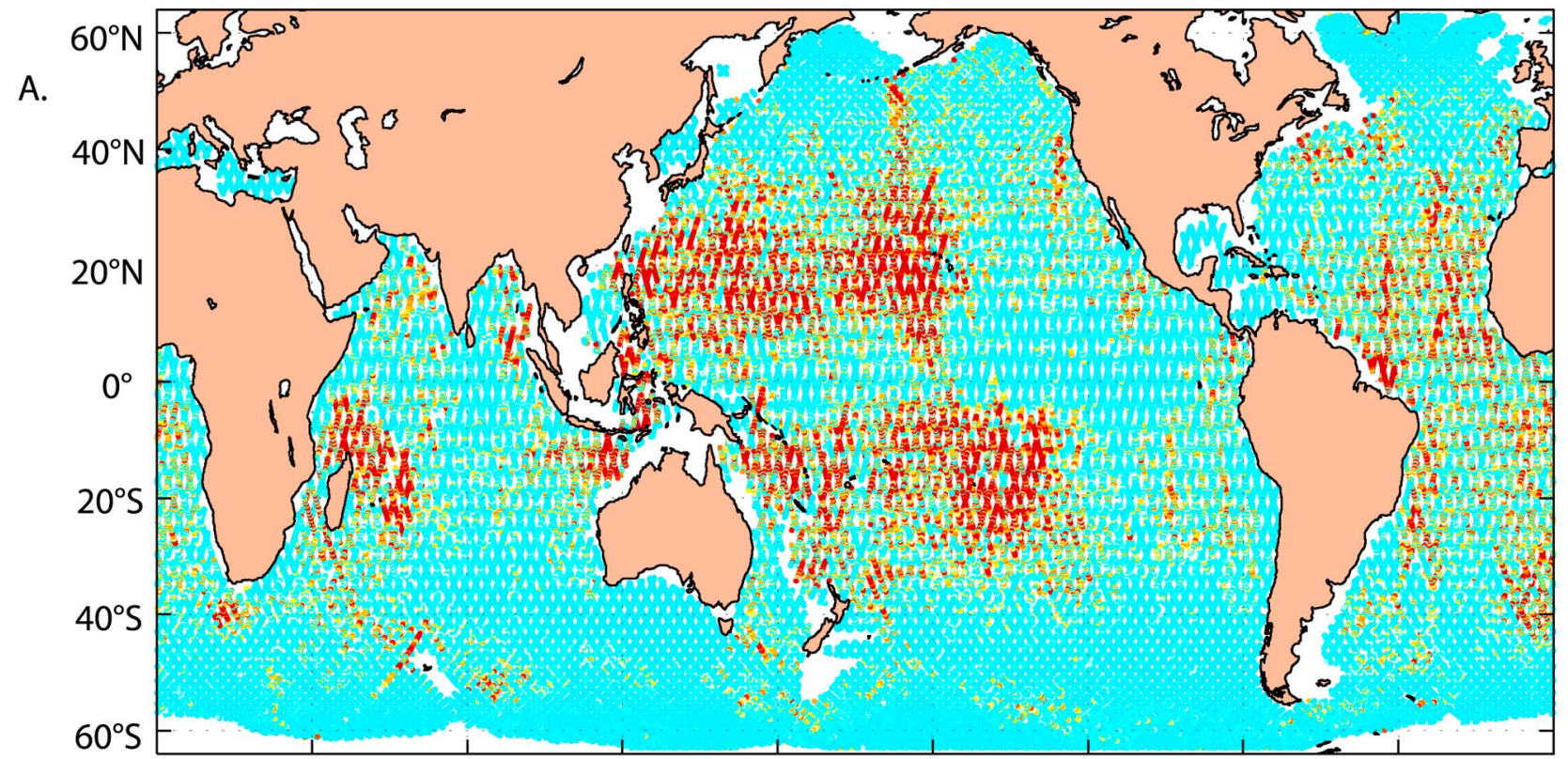

B.
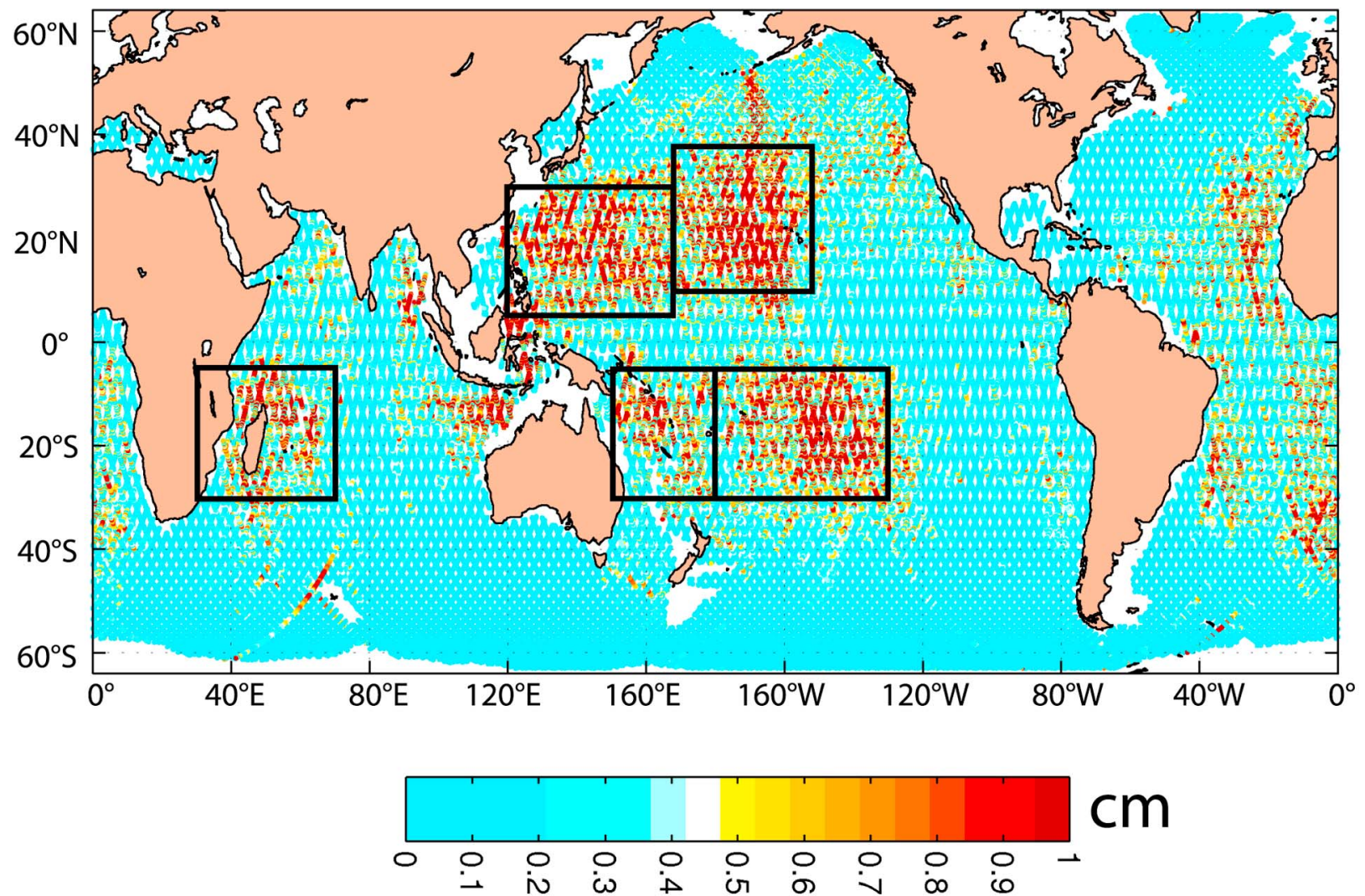

Figure 7. The $\mathrm{M}_{2}$ internal tide amplitude from the (a) altimetric-based and (b) HYCOM tidal analyses. The five subregions denoted by black boxes in Figure $7 \mathrm{~b}$ are used to compute the area-averaged amplitudes in Table 2.

where $A$ and $\phi$ are tidal amplitude and phase, respectively. The MSE for the eight constituents forced in the model are given in Table 1 with total MSE of $9.52 \mathrm{~cm}$ and MSE for the leading semidiurnal constituent $\left(\mathrm{M}_{2}\right)$ of $7.48 \mathrm{~cm}$ and leading diurnal constituent $\left(\mathrm{K}_{1}\right)$ of $2.25 \mathrm{~cm}$. The geographical distribution of the MSE for $\mathrm{M}_{2}$ and $\mathrm{K}_{1}$ are shown in Figures $4 \mathrm{a}$ and 5a. The semidiurnal errors are largest around the continental margins and Southern Ocean where differences in the bathymetry of TPXO and our model are the largest. Two large regions of error are found in the central 
Table 2. Area-Averaged Amplitudes of Semidiurnal Internal Tides From the Altimetric-Based (Upper Value) and HYCOM (Lower Value) Tidal Analyses Computed Over the Five Subregions Depicted in Figure $7 b^{a}$

\begin{tabular}{|c|c|c|c|c|}
\hline & $\mathrm{M}_{2}$ & $\mathrm{~S}_{2}$ & $\mathrm{~K}_{2}$ & $\mathrm{~N}_{2}$ \\
\hline \multicolumn{5}{|l|}{ Hawaii } \\
\hline Altimeter & 0.805 & 0.414 & 0.127 & 0.209 \\
\hline HYCOM & 0.887 & 0.509 & 0.146 & 0.162 \\
\hline \multicolumn{5}{|c|}{ East of Philippines } \\
\hline Altimeter & 0.837 & 0.399 & 0.121 & 0.226 \\
\hline HYCOM & 0.810 & 0.436 & 0.160 & 0.174 \\
\hline \multicolumn{5}{|c|}{ Tropical South Pacific } \\
\hline Altimeter & 0.843 & 0.271 & 0.083 & 0.200 \\
\hline HYCOM & 0.806 & 0.283 & 0.089 & 0.163 \\
\hline \multicolumn{5}{|c|}{ Tropical SW Pacific } \\
\hline Altimeter & 0.758 & 0.386 & 0.115 & 0.207 \\
\hline HYCOM & 0.617 & 0.315 & 0.111 & 0.141 \\
\hline \multicolumn{5}{|l|}{ Madagascar } \\
\hline Altimeter & 0.715 & 0.407 & 0.122 & 0.192 \\
\hline HYCOM & 0.665 & 0.357 & 0.124 & 0.128 \\
\hline \multicolumn{5}{|c|}{ Rest of world ocean ${ }^{b}$} \\
\hline Altimeter & 0.024 & 0.242 & 0.082 & 0.132 \\
\hline HYCOM & 0.006 & 0.001 & 0.005 & 0.004 \\
\hline
\end{tabular}

${ }^{\mathrm{a}}$ The five subregions are hot spots for generation of semidiurnal tides. Units are in centimeters.

${ }^{b}$ Denotes the area-averaged amplitude for the rest of the world ocean outside the five hot spot regions.

North and South Pacific. For the diurnal tides the errors are largest around the continental margins and over much of the Atlantic, Indian and Southern Oceans. The errors in the tidal elevations can arise from a combination of errors in the amplitude $A$ and the phase $\phi$. The MSE in (1) can be rewritten as

$$
\begin{aligned}
M S E= & \frac{1}{2}\left(\left(A_{H Y C O M} \cos \phi_{H Y C O M}-A_{T P X O} \cos \phi_{T P X O}\right)^{2}\right. \\
& \left.+\left(A_{H Y C O M} \sin \phi_{H Y C O M}-A_{T P X O} \sin \phi_{T P X O}\right)^{2}\right),
\end{aligned}
$$

where MSE consists of contributions resulting from differences from the in phase (cosine) and quadrature (sine) terms for the constituent of interest. For all constituents, the global MSE is approximately equally divided between the in phase and quadrature terms. For the semidiurnal tide, the large central North Pacific error is predominately in phase and the central South Pacific is predominately in quadrature (maps not shown). However, significant quadrature errors in the North Pacific and in phase errors in the South Pacific are found in the same regions.

[17] We are not just interested in the generation of barotropic and internal tides, but how errors in the barotropic tide translate into errors in the internal tides. As an alternative to (2), we can partition the MSE into contributions from differences in the amplitude only and from the cosine of the differences in the phases weighted by the geometric mean of the amplitudes (amplitude-weighted phase errors),

$$
\begin{aligned}
M S E= & {\left[\frac{1}{2}\left(A_{\text {HYCOM }}-A_{\text {TPXO }}\right)^{2}\right] } \\
& +\left[A_{\text {HYCOM }} A_{\text {TPXO }}\left(1-\cos \left(\phi_{\text {HYCOM }}-\phi_{\text {TPXO }}\right)\right)\right],
\end{aligned}
$$

with the first term on the right hand side denoting a contribution to the surface tidal elevation error resulting from errors in tidal amplitude only ( $\left.\mathrm{MSE}_{\text {amplitude }}\right)$ and the second term $\left(\mathrm{MSE}_{\text {phase }}\right)$ from errors in the amplitude-weighted phase. As can be seen from (3), if either model has small amplitude, then the amplitude-weighted phase error will be small regardless the difference in phase. To illustrate the value of this partitioning, consider the case of two sine waves which differ only in phase. From (2), the relative contributions to the in phase and quadrature errors will vary depending upon the phase difference. However, from (3), the amplitude error, $\mathrm{MSE}_{\text {amplitude }}$, will be zero regardless of the phase difference and the error will be only in the amplitude-weighted phase $\mathrm{MSE}_{\text {phase }}$. Maps of the total (MSE), amplitude (MSE amplitude $_{\text {) and amplitude-weighted }}$ phase $\left(\mathrm{MSE}_{\text {phase }}\right)$ errors for $\mathrm{M}_{2}$ and $\mathrm{K}_{1}$ are shown in Figures 4 and 5 . The globally averaged statistics for all eight constituents in HYCOM are listed in Table 1 with the errors approximately evenly split between amplitude and phase. However, unlike the in phase and quadrature errors from (2), for the $\mathrm{M}_{2}$ tide, the large error regions in the Pacific are predominately amplitude-weighted phase errors. The barotropic tide generates the baroclinic tides through topographic interactions. These generation regions are not uniformly distributed around the globe. In particular, large barotropic phase errors in the Pacific generation regions will lead to large baroclinic phase errors associated with the timing of the generation of the internal tide. Thus, the MSE for the internal tides will be large due to the timing errors, while the amplitudes will compare well.

[18] When the model barotropic tide is compared to the 102 pelagic gauges described by Shum et al. [1997], the RMS errors increase slightly to $7.80 \mathrm{~cm}$ for $\mathrm{M}_{2}$ and $10.22 \mathrm{~cm}$ for all eight constituents, but are still lower than in the work by Arbic et al. [2004, 2010]. Data assimilation for TPXO reduces the errors in the shallow water tidal models relative to the 102 pelagic gauges to $\sim 1.6 \mathrm{~cm}$ for $\mathrm{M}_{2}$ and $\sim 3 \mathrm{~cm}$ for the eight constituents [Shum et al. 1997]. When compared to a data-assimilative model (TPXO7.2), our model tides are comparable to other nonassimilative shallow water tide models, $\sim 7 \mathrm{~cm}$ [Jayne and St. Laurent, 2001; Arbic et al., 2004] and $\sim 5 \mathrm{~cm}$ for $\mathrm{M}_{2}$ [Egbert et al., 2004]. Note that Jayne and St. Laurent [2001], Arbic et al. [2004], and Egbert et al. [2004] all utilized a rigorous (i.e., nonscalar) SAL correction, in contrast to the HYCOM results shown here. Egbert et al. [2004] find that 5-10\% random errors in the bathymetry can lead to $\sim 8 \mathrm{~cm}$ RMS differences in the $\mathrm{M}_{2}$ amplitude.

\subsection{Internal Tide}

[19] The barotropic tides interact with topography to generate internal tides. Thus, errors in the barotropic tides or bathymetry will lead to errors in the internal tides. Globally, the barotropic tide errors are split almost evenly between amplitude and phase errors. Since phase errors in the barotropic tide will cause phase errors in the baroclinic tides, the traditional RMS error statistic for the baroclinic tidal heights may not be a good measure of the model performance. For example, consider the $\mathrm{M}_{2}$ internal tides in the northeastern Pacific, shown in Figure 6, where the amplitude of the $\mathrm{M}_{2}$ internal tides from the model (red) and altimeter (black) are plotted. Qualitatively, the amplitudes of the 

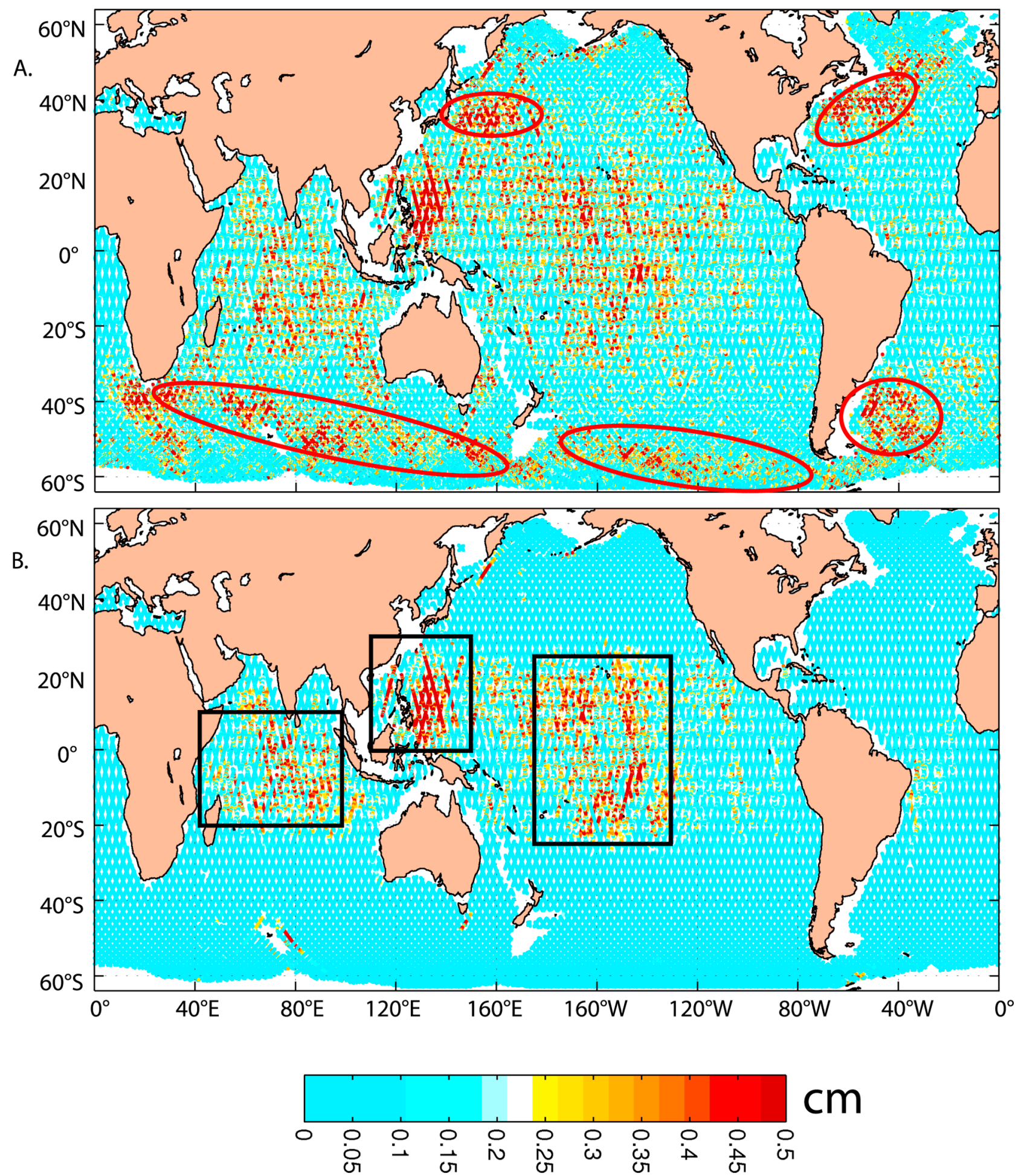

Figure 8. The $\mathrm{K}_{1}$ internal tide amplitude from the (a) altimetric-based and (b) HYCOM tidal analyses. Areas where mesoscale variability contaminates the altimetric-based tidal analysis are identified by the red circles in Figure 8a. The three subregions denoted by black boxes in Figure $8 \mathrm{~b}$ are used to compute the area-averaged amplitudes in Table 3. 
Table 3. As in Table 2 but for the Three Subregions Depicted in Figure 8b, Which Are Hot Spots for Diurnal Internal Tides ${ }^{\mathrm{a}}$

\begin{tabular}{lcccc}
\hline & $\mathrm{K}_{1}$ & $\mathrm{O}_{1}$ & $\mathrm{P}_{1}$ & $\mathrm{Q}_{1}$ \\
\hline $\begin{array}{l}\text { Central Indian Ocean } \\
\text { Altimeter }\end{array}$ & 0.275 & 0.185 & 0.089 & 0.112 \\
$\quad$ HYCOM & 0.264 & 0.149 & 0.096 & 0.039 \\
Philippines & & & & \\
$\quad$ Altimeter & 0.402 & 0.320 & 0.125 & 0.140 \\
$\quad$ HYCOM & 0.395 & 0.341 & 0.153 & 0.073 \\
Central Tropical Pacific & & & & \\
$\quad$ Altimeter & 0.251 & 0.183 & 0.081 & 0.107 \\
$\quad$ HYCOM & 0.243 & 0.181 & 0.117 & 0.046 \\
Rest of world ocean equatorward & & & & \\
$\quad$ of 30 & & & & \\
$\quad$ Altimeter & 0.180 & 0.148 & 0.060 & 0.101 \\
HYCOM & 0.123 & 0.092 & 0.056 & 0.029 \\
\hline
\end{tabular}

${ }^{\mathrm{a}}$ Note that the average amplitudes for the diurnal tides are calculated equatorward of $30^{\circ}$ only. Units are in centimeters.

observed altimetric tide and model tide agree well with RMS amplitudes of $0.361 \mathrm{~cm}$ and $0.346 \mathrm{~cm}$ for the altimeter and model, respectively. However, RMS error of the complex amplitudes, including the phase of the tides, is $0.232 \mathrm{~cm}$. If we partition this difference into amplitude and phase errors following (3), then the amplitude error is $0.128 \mathrm{~cm}$ while the phase error is $0.193 \mathrm{~cm}$. Thus, most of the differences between the model and altimeter internal tides arise from phase errors. Given the errors in the phase of the barotropic tide and model bathymetry errors, it is not very surprising that phase errors may dominate the internal tides. Making sure we convert the proper amount of energy from the barotropic tide into the baroclinic tide is an important first step in the evaluation of the model tides. We will therefore use the area-averaged absolute value of the amplitude as the statistic for our comparisons. Using the absolute value of the amplitude and areal averaging reduces the sensitivity of the statistics to phase errors.

[20] The global $\mathrm{M}_{2}$ along-track altimetric tidal analysis (Figure 7a) exhibits several internal tide generation regions ("hot spots") near Madagascar, Hawaii, east of the Philippines and the tropical south and southwest Pacific. Internal tides radiating over long distances are also evident, for example between the Aleutian Islands and the Hawaii hot spot [e.g., Cummins et al., 2001]. Amplitudes fall sharply and are relatively low outside these hot spot regions, although close analysis can reveal internal tide signals even in "quiet" regions such as the southeast Pacific. HYCOM exhibits similar features to those noted in the altimetric tidal analysis (Figure 7b).

[21] To quantitatively assess how well the internal tide results from HYCOM compare with the altimetric-based analysis, area-averaged amplitude is computed over five subregions centered on internal tide generation regions (black boxes in Figure 7b). In addition, area-averaged statistics are also computed over the world ocean outside of these five hot spot regions. All four semidiurnal constituents largely share these hot spot regions, and summary statistics for these constituents are shown in Table 2 .

[22] The area-averaged amplitude is found to agree well across the five hot spot subregions for the four semidiurnal constituents. The average percent discrepancy ((|hycom altim $|/|$ altim $\mid) \times 100$ ) across the five hot spot subregions for all four constituents is $\sim 15 \%$, with $\mathrm{M}_{2}$ having the lowest average percent discrepancy $(\sim 9 \%)$ and $\mathrm{N}_{2}$ having the highest
( $\sim 26 \%$ ). Across the four semidiurnal constituents the largest discrepancy is noted for the world ocean outside of the five hot spot regions, where the average percent discrepancy is $\sim 91 \%$ with the model underestimating the internal tide energy compared to the altimeter. Inaccuracies in the simulated barotropic tide, which generates the internal tide, account for part of the discrepancy. For example, the model internal tides are too weak in the North Atlantic, where the model barotropic tide is weaker than the data-assimilative barotropic tide (Figure 2). Another source of the discrepancies, mesoscale leakage, will be discussed later in this section.

[23] The global $\mathrm{K}_{1}$ internal tide amplitudes from the altimetric analysis and HYCOM are shown in Figure 8. The altimetric and HYCOM tidal analyses exhibit three main hot spot regions: near the Philippines, the central Indian Ocean and the central tropical Pacific. The average percent discrepancy across the three hot spot subregions for all four diurnal constituents (Table 3 ) is $\sim 23 \%$, with $\mathrm{K}_{1}$ having the lowest average percent discrepancy $(\sim 3 \%)$ and $\mathrm{Q}_{1}$ having the highest $(\sim 57 \%)$. Across the four diurnal constituents the average percent discrepancy for the world ocean outside of the three hot spot regions and equatorward of $30^{\circ}$ is $\sim 37 \%$.

[24] Poleward of $30^{\circ}$ latitude the altimetric-based tidal analysis exhibits significantly higher amplitudes than the HYCOM analysis (Figure 8). These high-amplitude areas (circled regions in Figure 8a) coincide with areas of highmesoscale activity, including the Kuroshio, Gulf Stream, Antarctic Circumpolar Current (ACC) and Brazil-Malvinas confluence. This pattern is consistent across all four of the diurnal constituents.

[25] As mentioned in the introduction, propagating diurnal internal tides do not exist poleward of approximately $30^{\circ}$ [Gill, 1982]. HYCOM diurnal tidal amplitudes obtained from hourly samples satisfy this theoretical constraint (Figure 8b). However, as discussed in the literature [Tierney et al., 1998; Carrère et al., 2004; Ray and Byrne, 2010], the altimetric analysis (Figure 8a) shows features that result from the leakage of mesoscale activity into tidal frequency estimates. This leakage is visually evident across all the diurnal constituents, where internal tides do not propagate, and it can be seen in the semidiurnal constituents as well. For example, mesoscale leakage can be clearly seen in $\mathrm{S}_{2}$ altimetric internal tidal amplitudes (Figure 9a), with large amplitudes in the Kuroshio, Gulf Stream and ACC regions not present in HYCOM (Figure 9b). It is worth emphasizing, however, the extremely small amplitudes in both Figures 8 and 9. In each case the color bar spans only $5 \mathrm{~mm}$. It is thus understandable that detection and mapping of such small signals is extremely challenging for satellite altimetry, even after almost two decades of data.

[26] Quantitative evidence of mesoscale leakage in the semidiurnal constituents is also evident in Table 2, where the average percent discrepancy over the world ocean outside of the hot spot regions is $80 \%$. This discrepancy is significantly higher than the diurnal case $(\sim 37 \%)$ because the latter statistic was computed over the $30^{\circ} \mathrm{S}-30^{\circ} \mathrm{N}$ latitude range, effectively filtering out large areas of mesoscale leakage (e.g., Gulf Stream, Kuroshio, ACC).

\section{Summary and Conclusions}

[27] The potential for the realistic simulation of barotropic and internal tides in a high-resolution global ocean 

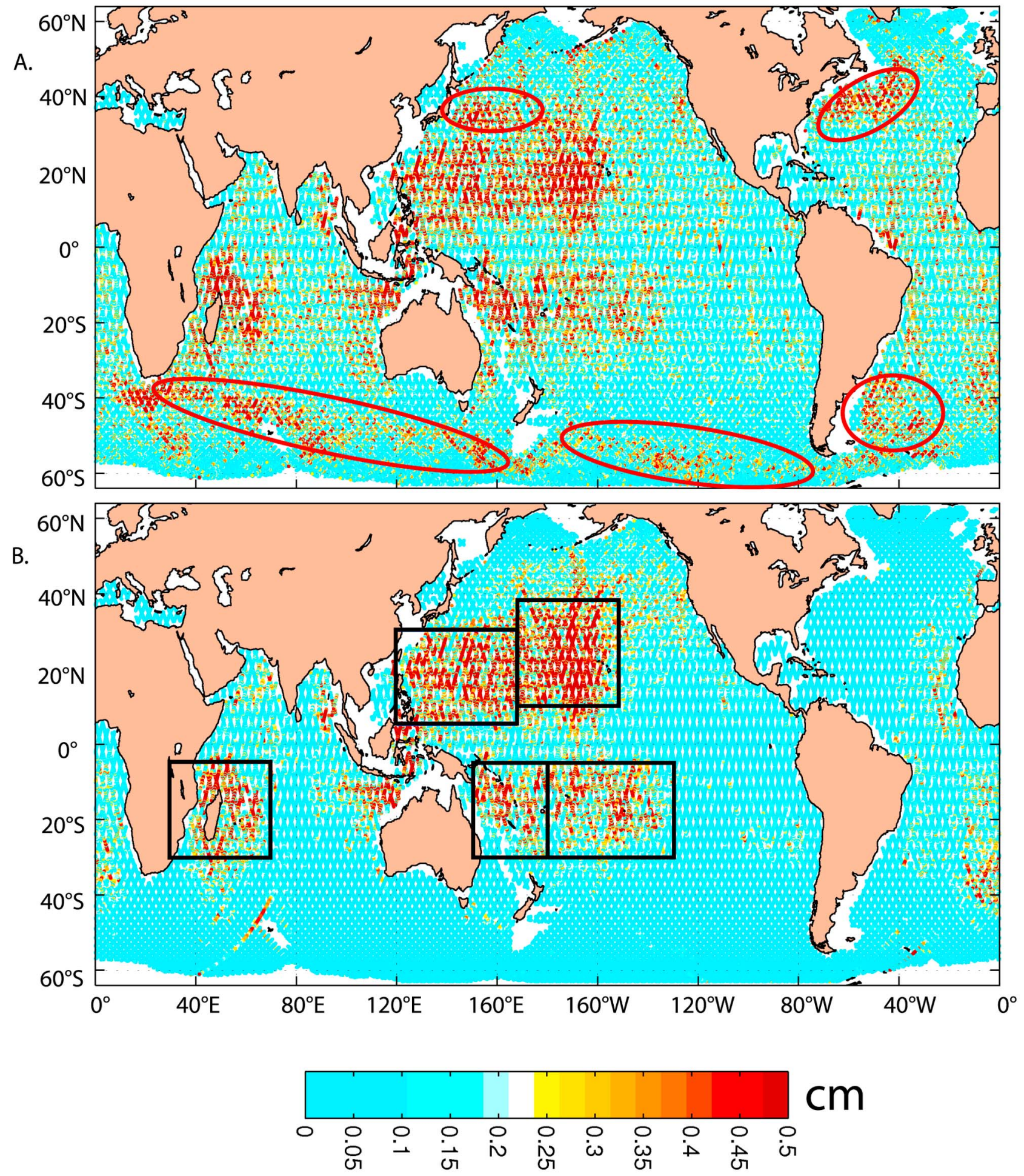

Figure 9. The $\mathrm{S}_{2}$ internal tide amplitude from the (a) altimetric-based and (b) HYCOM tidal analyses. Areas where mesoscale variability contaminates the altimetric-based tidal analysis are identified by the red circles in Figure 9a.

circulation model is examined using results from year 2006 of a seven and a half year $1 / 12.5^{\circ}$ global simulation of HYCOM that resolves internal tides, along with barotropic tides and the eddying general circulation. Barotropic tides from HYCOM are compared with barotropic tides from an altimetry-constrained barotropic tide model (TPXO7.2; an update to that described by Egbert et al. [1994]). The HYCOM barotropic tides are comparable in amplitude and phase to other nonassimilative tidal models. The errors in the HYCOM barotropic tide are split almost evenly between 
amplitude and phase errors. Internal tide amplitudes from HYCOM are compared with results from a TOPEX/POSEIDON-Jason along-track altimetric tidal analysis [Ray and Mitchum, 1996; Ray and Zaron, 2011]. This work is the first global quantitative comparison of the simulated internal tide field to an observed data set. The area-averaged internal tide amplitudes over the energetic tidal regions are found to be quite similar to those in along-track satellite altimeter data for seven of the eight tidal constituents in HYCOM, with $\mathrm{Q}_{1}$ exhibiting the poorest agreement. $\mathrm{Q}_{1}$ is the smallest amplitude tidal constituent and suffers from a poor signal-to-noise ratio in the altimeter data.

[28] Away from the hot spots, the comparison between the model and altimetric amplitude is not as good due, in part, to two problems, errors in the model barotropic tides and overestimation of the altimetric tides in regions of strong mesoscale eddy activity due to leakage of this activity into the altimetric tidal analysis. This leakage affects all constituents and is probably unavoidable, owing to limitations in time sampling, especially at the very small ( $\mathrm{mm} \mathrm{level)}$ signal amplitudes of some internal tides. Research into further understanding deficiencies in the barotropic tides, and hence the internal tides, in HYCOM is ongoing.

[29] These results represent an encouraging first step in the modeling of internal tides in a global ocean model that also resolves the barotropic tides and eddying general circulation. This model, forced only by atmospheric forcing and the astronomical tidal potential, is able to generate internal waves over energetic tidal regions statistically consistent with observations without the benefit of data assimilation. Improvements to the accuracy of the simulated internal tide are likely to arise from finer horizontal resolution, which leads to better resolved and represented oceanic features that affect stratification. Reducing the errors in the simulated barotropic tide and improving the accuracy of the bottom topography that plays a key role in internal tide generation will also help. These improvements are presently underway in our global HYCOM development effort.

[30] Acknowledgments. J.F.S., J.G.R., E.J.M., and A.J.W. were supported by the project "Eddy Resolving Global Ocean Prediction Including Tides" sponsored by the Office of Naval Research (ONR) under program element number 0602435 N. B.K.A. and P.G.T. acknowledge support from Naval Research Laboratory contract N000173-06-2-C003 and ONR grants N00014-09-1-1003 and N00014-11-1-0487. The model results were obtained under the FY09-11 Department of Defense HPC Challenge Project "Eddy Resolving Global Ocean Prediction including Tides." This is NRL contribution NRL/JA/7320-12-1201.

\section{References}

Arbic, B. K., S. T. Garner, R. W. Hallberg, and H. L. Simmons (2004), The accuracy of surface elevations in forward global barotropic and baroclinic tide models, Deep Sea Res., Part II, 51, 3069-3101, doi:10.1016/j.dsr2.2004.09.014.

Arbic, B. K., A. J. Wallcraft, and E. J. Metzger (2010), Concurrent simulation of the eddying general circulation and tides in a global ocean model, Ocean Modell., 32, 175-187, doi:10.1016/j.ocemod.2010.01.007.
Carrère, L., C. Le Provost, and F. Lyard (2004), On the statistical stability of the $\mathrm{M}_{2}$ barotropic and baroclinic tidal characteristics from along-track TOPEX/POSEIDON satellite altimetry analysis, J. Geophys. Res., 109, C03033, doi:10.1029/2003JC001873.

Cartwright, D. E., and R. D. Ray (1990), Oceanic tides from Geosat altimetry, J. Geophys. Res., 95, 3069-3090, doi:10.1029/JC095iC03p03069.

Cummins, P. F., J. Y. Cherniawsky, and M. G. G. Foreman (2001), North Pacific internal tides from the Aleutian ridge: Altimeter observations and modeling, J. Mar. Res., 59, 167-191, doi:10.1357/002224001762882628.

Egbert, G. D., and R. D. Ray (2000), Significant dissipation of tidal energy in the deep ocean inferred from satellite altimeter data, Nature, 405, 775-778, doi: $10.1038 / 35015531$.

Egbert, G. D., A. F. Bennett, and M. G. G. Foreman (1994), TOPEX/ POSEIDON tides estimated using a global inverse model, J. Geophys. Res., 99, 24,821-24,852, doi:10.1029/94JC01894.

Egbert, G. D., R. D. Ray, and B. G. Bills (2004), Numerical modeling of the global semidiurnal tide in the present day and in the Last Glacial Maximum, J. Geophys. Res., 109, C03003, doi:10.1029/2003JC001973.

Foreman, M. G. G. (1977), Manual for tidal heights analysis and prediction, edited by P. Bay, Pac. Mar. Sci. Rep. 77-10, 66 pp., Inst. of Ocean Sci., Ottawa, Ont., Canada.

Gill, A. E. (1982), Atmosphere-Ocean Dynamics, 662 pp., Academic, San Diego, Calif.

Jayne, S. R., and L. C. St. Laurent (2001), Parameterizing tidal dissipation over rough topography, Geophys. Res. Lett., 28, 811-814, doi:10.1029/ 2000GL012044.

Kang, S.-K., M. G. G. Foreman, W. R. Crawford, and J. Y. Cherniawsky (2000), Numerical modeling of internal tide generation along the Hawaiian Ridge, J. Phys. Oceanogr., 30, 1083-1098, doi:10.1175/1520-0485(2000) 030<1083:NMOITG $>2.0 . \mathrm{CO} ; 2$.

Merrifield, M. A., P. E. Holloway, and T. M. Shaun Johnston (2001), The generation of internal tides at the Hawaiian Ridge, Geophys. Res. Lett., 28, 559-562, doi:10.1029/2000GL011749.

Metzger, E. J., H. E. Hurlburt, X. Xu, J. F. Shriver, A. L. Gordon, J. Sprintall, R. D. Susanto, and H. M. van Aken (2010), Simulated and observed circulation in the Indonesian Seas: $1 / 12^{\circ}$ global HYCOM and the INSTANT observations, Dyn. Atmos. Oceans, 50, 275-300, doi:10.1016/j.dynatmoce. 2010.04.002.

Pascual, A., Y. Faugre, G. Larnicol, and P.-Y. Le Traon (2006), Improved description of the ocean mesoscale variability by combining four satellite altimeters, Geophys. Res. Lett., 33, L02611, doi:10.1029/2005GL024633.

Ray, R. D. (1998), Ocean self-attraction and loading in numerical tidal models, Mar. Geod., 21, 181-192, doi:10.1080/01490419809388134.

Ray, R. D., and D. A. Byrne (2010), Bottom pressure tides along a line in the southeast Atlantic Ocean and comparisons with satellite altimetry, Ocean Dyn., 60, 1167-1176, doi:10.1007/s10236-010-0316-0.

Ray, R. D., and G. T. Mitchum (1996), Surface manifestation of internal tides generated near Hawaii, Geophys. Res. Lett., 23, 2101-2104, doi:10.1029/96GL02050.

Ray, R. D., and E. D. Zaron (2011), Non-stationary internal tides observed with satellite altimetry, Geophys. Res. Lett., 38, L17609, doi:10.1029/ 2011 GL048617.

Ray, R. D., G. D. Egbert, and S. Y. Erofeeva (2011), Tide predictions in shelf and coastal waters: Status and prospects, in Coastal Altimetry, edited by S. Vignudelli et al., pp. 191-216, Springer, Berlin, doi:10.1007/978-3-642-12796-0_8.

Rosmond, T. E., J. Teixeira, M. Pēng, T. F. Hogan, and R. Pauley (2002), Navy Operational Global Atmospheric Prediction System (NOGAPS): Forcing for ocean models, Oceanography, 15, 99-108, doi:10.5670/ oceanog. 2002.40

Shum, C. K., et al. (1997), Accuracy assessment of recent ocean tide models, J. Geophys. Res., 102, 25,173-25,194, doi:10.1029/97JC00445.

Simmons, H. L., R. W. Hallberg, and B. K. Arbic (2004), Internal wave generation in a global baroclinic tide model, Deep Sea Res., Part II, 51, 3043-3068, doi:10.1016/j.dsr2.2004.09.015.

Tierney, C. C., M. E. Parke, and G. H. Born (1998), An investigation of ocean tides derived from along-track altimetry, J. Geophys. Res., 103, 10,273-10,287, doi:10.1029/98JC00448. 